\title{
Erkek Geriatriklerde Anımsama Terapisinin Yaşlılığa Uyum ve Yaşam Kalitesine Etkisinin İncelenmesi: Kontrollü Çalışma
}

\author{
Examination of The Effects of Reminiscence Therapy in Adaptation to Aging and Quality of \\ Life on Geriatric Males
}

Zeynep Şule KURTULGAN ${ }^{1}$, Gamze EKICi ${ }^{2}$

${ }^{1}$ Erg., Hacettepe Üniversitesi Sağlık Bilimleri Fakültesi Ergoterapi Bölümü, Ankara, Türkiye

${ }^{2}$ Prof. Dr., Hacettepe Üniversitesi Sağlık Bilimleri Fakültesi Ergoterapi Bölümü, Ankara, Türkiye

\section{öz}

\begin{abstract}
Amaç: Bu çalışma erkek geriatrik bireylerde uygulanan anımsama terapisi'nin, yaşam kalitesi ve yaşlıı̆ga uyum düzeyleri üzerine olan etkisini incelemek amacıyla planlandı. Gereç ve Yöntem: Bu çalışmaya 15'i anımsama terapisi, $15^{\prime} \mathrm{i}$ ise kontrol grubunda olmak üzere toplamda 30 geriatrik erkek birey dahil edildi. Sosyo-demografik bilgileri kaydedildi. Yaşlıığa uyum düzeyleri "Yaşlılığa Uyum Güçlüğü Değerlendirme Ölçeği (YUGDÖ)" ile, yaşam kalitesi ise "Dünya Sağlık Örgütü Yaşam Kalitesi Yaşı Modülü (WHOQOLOLD)" ile değerlendirildi. Anımsama terapisi 4 hafta, haftada 3 kez toplam 12 seans uygulandı. Kendine bakımı, serbest zamanı ve üretkenliği içeren yaşamının tümünü kapsayan bir yaklaşımla çocukluk anıları, aile yaşamı, okul dönemi, gençlik anıları, seyahatler, bayramlar, iş hayatı, evlilik ve çocuklar, gelecek ile ilgili düşünceler başıklarına odaklanıldı. Anımsama terapisi sonrası aynı değerlendirmeler uygulandı. Sonuçlar: Anımsama terapisi öncesi ve sonrası karşılaşıtııldığında bireylerin yaşlılı̆a uyum düzeyi $(p=0,001)$; yaşam kalitesi parametrelerinden özerklik $(p=0,001)$, geçmiş, bugün, gelecek faaliyetleri $(p=0,001)$, sosyal katılım $(p=0,001)$, yakınlık $(p=0,001)$ ve toplam puanda $(p=0,001)$ iyileşme görüldü. Duyusal işlevler, ölüm ve ölmek başlıklarında ise istatistiksel anlamlı bir sonuç bulunmadı. Tartışma: Anımsama terapisi'nin, yaşlılığa uyumu ve yaşam kalitesini iyileştirmesi nedeniyle geriatrik döneme geçiş yapan erkeklerde rutin olarak uygulanması faydalı olacaktır.
\end{abstract}

Anahtar Kelimeler: Yaşısı; Yaşam kalitesi; Uyum

\section{ABSTRACT}

Purpose: This study was planned to investigate the effect of Reminiscence Therapy (RT) on quality of life (QOL) and adaptation to aging in male geriatric individuals. Material and Methods: Total of 30 geriatric males was included in this study, 15 of whom was RT and 15 of which were in the control group. Their socio-demographic data were recorded. Aging adaptation levels were evaluated with "Assessment Scale of Adaptation Difficulty for the Elderly (ASADE)", and QOL was evaluated with WHOQOL-OLD. RT was administered for 4 weeks, 3 times a week during 12-sessions. With an approach that covers the whole life including self-care, leisure time, productivity, we focused on childhood memories, family life, school period, youth memories, travels, holidays, business life, marriage and children, thoughts about the future titles. Same evaluations were performed after RT. Results: After RT, improvements were seen in the adaptation level of the individuals to aging $(p=0.001)$; autonomy $(p=0.001)$, past, present and future abilities $(p=0.001)$, social participation $(p=0.001)$, intimacy $(p=0.001)$ and total score $(p=0.001)$. There was no statistical significance in sensory abilities; death and dying. Conclusion: It will be beneficial to use RT routinely in males who are in the geriatric period because it will help them adapt to aging and improve QOL.

Keywords: Elderly; Quality of Life; Adaptation 
Dünya Sağlık Örgütü (DSÖ), yaşlılığı kişinin çevresel faktörlere uyum sağlayabilme yeteneğinin azalması olarak tanımlamaktadır (Kutsal, 2003). Toplumların nüfus dağılımları incelendiğinde, yaşlı nüfusun her yıl artmakta olduğu görülmektedir. Yaşlı nüfustaki artış sebebiyle yaşlılıkla ilgili problemler daha fazla karşımıza çıkmaya başlamıştır. Bu problemlerin bir kısmı yaşıının kendi fiziksel ve psikolojik durumuyla ilgili olurken bir kısmı ise çevresel faktörlerden kaynaklanmaktadır (Kurt, Yücel Beyaztaş ve Erkol, 2010).

Kişiler yaşlılık döneminde daha fazla kronik hastalık ile baş etmek durumda kalmaktadır. Geriatrik bireylerde karşılaşılan bu hastalıkların başında demans, alzheimer, osteoporoz, sık düşme gibi sorunlar gelir. Bunların yanında görme, işitme, yürüme ve uyku bozuklukları da önemli sorunlardır (Güven, Şener ve Gürsoy, 2011). Kronik hastalıklarla birlikte yaşlıların psikolojik ve soysal açıdan da etkilenimleri görülmektedir. Bu etkilenimlerden rol değişimi/rol kaybı, stres yaratan durumlarla baş edebilmede zorluk, kendine güven ve verimliliğin azalması, iletişim becerilerinde azalma ve topluma adaptasyon sağlamada zorluk gibi durumlar en sık karşılaşılanlardır (Görgünbaran, 2008).

Yaşlılık döneminde karşılaşılan sorunlar, geriatrik bireyin yaşam memnuniyetini, çevresi ve kendisiyle uyumunu olumsuz yönde etkilemektedir (Proietti, Compagnone ve Liotta, 2014). Insan yaşamı sürekli devinim halinde olduğu için uyum her çağda anlamlı ve aktif bir yaşam için gerekli bir süreçtir. Yaşılık fiziksel ve bilişsel gerilemeler, emeklilik, ayrılıklar, kayıplar ve yaşamın sonunun yaklaşması gibi hayatın kritik dönemlerini içinde barındırmaktadır. Kritik dönemlerle baş edebilmek için uyum bu yaş grubunda önemli kabul edilmektedir. Yaşııı̆̆a uyum problemi yaşandığında geriatrik bireylerde yalnızlık, anksiyete, umutsuzluk, depresyon, ölüm korkusu gibi psikolojik sorunlarla karşılaşılmakta ve yaşam kalitesi olumsuz yönde etkilenmektedir (Cangöz, 2009; Ouwehand, de Ridder ve Bensing, 2007; Gignac, Cott ve Badley, 2002; Bowling, 2007). Bu problemlerle başa çıkma stratejilerinin oluşturulması için sağıkılı yaşlanmanın sağlanması gerekmektedir.

Sağlıklı yaşlanma için bireyin kendini yaşlıı̆ga hazırlama sürecinde sosyal çevresini ve ilişkilerini canlı tutması, bellek ve fiziksel işlevlerini geliştirici aktivitelerde bulunması ve yaşama olumlu bakması için gerekli motivasyonun arttırılması gerekmektedir (Görgünbaran, 2008).

Literatürde geriatrik bireylerin yaşam kalitelerinin arttırılması ve yaşlılığa uyumun geliştirilmesi ile ilgili çeşitli çalışmalar bulunmaktadır. Geriatrik rehabilitasyon, geriatrik bireylere sunulan danışmanlık uygulamaları, sosyal hizmet çalışmaları, sanat terapisi ve anımsama terapisi uygulanan çalışmalardandır (Çelebi ve Yüksel, 2014; Avaş ve Akçiçek, 2010; Bulduk, Dinçer, Usta ve ark, 2017).

Geriatrik bireylere yönelik sağığı geliştirme uygulamalarından birisi de anımsama terapisidir. Anımsama terapisi geriatrik bireylerin yaşlanma sürecine uyumunu sağlamak amacıyla psikososyal bir yaklaşım olarak uygulanmaktadır. Anımsama temelli aktiviteler geriatrik bireylerin yaşam kalitesini arttırmada olumlu etkilere sahiptir (Coleman, 2005; Liu, Lin, Chen ve ark, 2007; Lin, Dai ve Hwang, 2003).

Yaşılığın getirdiği sorunlarla karşılaşıldığında anımsama, sorunlarla baş etme stratejileri üretilmesinde önemli bir rol oynamaktadır. Uzun yıllar boyunca geriatrik bireylerin geçmişi anımsamaları bir uyumsuzluk ve geçmişte takılıp kalma gibi bir problem olarak değerlendirilmiştir. Fakat son 25 yıldır anımsamanın geriatrik bireylerde terapatik bir araç olarak kullanıldığı görülmektedir (Jonsdottir, Jonsdottir, Steingrimsdottir ve ark, 2001). $\mathrm{Bu}$ uygulama, geriatrik bireylere yönelik psikolojik hizmetler içerisinde zamanla önemli bir yere sahip olmuştur. Günümüzde yaygın olarak anımsama terapisi olarak uygulanmaya devam etmektedir. Yaygın uygulanışıyla anımsama terapisi, grup ortamında olumlu yaşantıların paylaşılmasıyla geriatrik bireylere kendilerini daha güçlü, değerli ve özgüvenli hissettirmeyi amaçlamaktadır (Haight ve Gibson, 2005). Ayrıca, güçlü yönlerin ve geçmişteki başarıların anımsanması, geriatrik bireylerin bugünkü sorunlarla baş etme becerilerini geliştirerek yaşlıı̆̆a uyumlarını artırmaktadır (Karimi, Dolatshahee, Momeni ve ark, 2010).

Anımsama terapisi geriatrik kadınlarda uygulanmış elde edilen başarı doğrultusunda da etkisinin erkek geriatriklerde de araştırılmasının üzerinde durulmuştur (Aşiret ve Dutkun, 2018). Bu öneriden yola çıkılarak, çalışmanın amacı geriatrik erkek bireylerde anımsama terapisi'nin yaşlıığa uyum ve yaşam kalitesi üzerindeki etkilerini incelemektir.

\section{GEREÇ VE YÖNTEM}

Çalışmamıza Eylül 2018-Haziran 2019 tarihleri arasından Mersin ve Ankara illerinde seçilen 30 gönüllü geriatrik erkek birey dahil edildi. Çalışmaya dahil edilme kriterleri 65 yaş üzerinde erkek olmak, Standardize Mini Mental Durum Testi'nden 
(SMMDT) 24'ün üzerinde puan almış olmak şeklinde belirlenmiştir. Dahil edilmeme kriterleri bireylerde bilinen herhangi bir nörolojik (Demans, Parkinson vb.) ve psikiyatrik hastalık (Şizofreni, Bipolar vb.) tanısının olmasıdır. 15 kişi müdahale grubuna, 15 kişi ise kontrol grubuna dahil edilmiştir. Çalışmaya katılan kişilere çalışma hakkında bilgi verilip, kabul edenlere Helsinki Deklerasyon prensiplerine uygun bilgilendirilmiş bir onam formu imzalatılmıştır. Çalışmaya katılan bireyler seans öncesi ve sonrası, 5 kişilik gruplar oluşturularak 12 seanslık anımsama terapisi sonrası olmak üzere iki defa değerlendirilmiştir. Katılımcılar, ortak özellikleri ve yaşam tarzları dikkate alınarak gruplara ayrılmıştır.

Veri Toplama Araçları

Çalışmaya katılan bireylerin öncelikle Sosyodemografik Bilgi Formu ile bilgileri alınmıştır. Kognitif düzeylerinin belirlenebilmesi için SMMDT uygulanmıştır. Yaşlılarda Uyum Güçlüğü Değerlendirme Ölçeği ile geriatrik bireylerin yaşlılığa uyumları değerlendirilmiştir. Dünya Sağlık Örgütü Yaşam Kalite Ölçeği- ile kişilerin yaşam kaliteleri değerlendirilmiştir.

1. Sosyodemografik Bilgi Formu; çalışmaya katılan geriatrik bireylerin; yaş, cinsiyet, eğitim durumu, çocuk sayısı, medeni durumu, yaşadığı yer, ilaç kullanımları ve hastalıklarının bilgileri kaydedildi.

2. Standardize Mini Mental Durum Testi; çalışmada bireylerin bilişsel durumlarını tespit etmek için mini mental durum testi kullanıldı. SMMDT, yönelim (toplam 10 puan), kayıt belleği (toplam 3 puan), dikkat ve hesap yapma (toplam 5 puan), hatırlama (toplam 3 puan) ve lisan (toplam 9 puan), başlıkları altında toplam 5 maddeden ve toplam 30 puandan oluşmaktadır. 24 puan değeri eşik değeri olarak kabul edilmekte ve bu değerin altındaki puanlar bilişsel fonksiyonlarda bozulmanın var olduğunu göstermektedir. Testin geçerlilik ve güvenirlilik çalışması Güngen ve arkadaşları tarafından yapılmıştır (Güngen, Ertan, Eker ve ark, 2002).

3. Yaşlılarda Uyum Güçlüğü Değerlendirme Ölçeği; Yaşlılarda Uyum Güçlüğü Değerlendirme Ölçeği (YUDGÖ) 24 maddeden ve toplam 72 puandan oluşmaktadır. Ölçeğin "Rol ve Kendini Gerçekleştirme Biçimi” (1, 5, 9, 12, 13, 14, 15, 16, 24. Maddeler) Karşılıklı Bağlanma" (17, 18, 19, 20, 21, 22, 23. Maddeler), Fizyolojik Durum" (2, 4, 10, 11. Maddeler) ve Benlik Tarzı" (3, 6, 7, 8. Maddeler) olmak üzere dört alt boyutu bulunmaktadır. Alınan puan 0'a yaklaştıkça uyum seviyesi yükselir. Anketin geçerlilik ve güvenirlilik çalışması Şişman ve Kutlu tarafından yapılmıştır (Şişman ve Kutlu, 2016).

\section{Dünya Sağlık Örgütü Yaşam Kalitesi Yaşı Modülü} (WHOQOL-OLD); yaşam kalitesi ölçeğinin Türkçe geçerlik ve güvenirlik çalışması Eser ve ark. (2004) tarafından yapılmış olup, ölçek 24 likert tipi madde ve 6 alt ölçekten/alandan oluşmaktadır. Bu alanlar duyusal işlevler, özerklik, geçmiş, bugün ve geleceğe ait aktiviteler, sosyal katılım, ölüm ve ölmek ve yakınlık başı̆̆ı ile yer almaktadır. Duyusal işlevler; görme, işitme, koku, tat alma, iştah ve dokunma duyularındaki değişikliklerin yaşam kalitesi üzerindeki etkisini, Özerklik; bağımsızlık, saygı, genel olarak yaşamı kontrol etme, özgür biçimde tercih yapma ve bu faktörlerin yaşam kalitesi üzerindeki etkisini, Geçmiş, bugün ve geleceğe ait aktiviteler; geçmişte elde edilen başarılar ve bu başarılardan yaşam boyu memnuniyet durumu, geçmişten söz edilmesi ve gelecek ile ilgili duygu ve düşünceleri sorgulamaktadır. Sosyal katılım; zamanı kullanma ile ilgili görüşler ve önemli faaliyetlere katılma durumu, Yakınlık; diğer kişilerle ilişkiler ve sosyal desteği; Ölüm ve ölmek alt alanında ise ölümün kabul edilebilir ve kaçınılmaz olması ile ilgili düşünceler ve ölümün anlamı araştırılmaktadır. Beşli likert ölçeği, 1: hiç, 2: çok az, 3: orta derecede, 4: çokça, 5: aşırı derecede şeklindedir. Her bir soru için olası en düşük puan 1, en yüksek puan 5'tir (Eser, Saatli, Eser ve ark, 2010).

\section{Müdahale}

Çalışmaya dahil edilen 30 geriatrik erkek bireyin 15 'ine haftada 3 kez 4 hafta olmak üzere 5 kişilik gruplar halinde toplam 12 seans anımsama terapisi uygulandı. Kontrol grubunda yer alan bireylere ise 4 hafta ara ile ikinci kez değerlendirme yapıldı. Anımsama terapisi kapsamında tanışma, çocukluğun geçtiği yer ve aile yaşamı, çocukluk oyunları, okul dönemine ait mutlu anılar, arkadaşlar ve öğretmenler, gençlik dönemine ait mutlu anılar, anısı olan seyahatler, bayramlar, iş hayatı, evlilik, çocuklar, değerlendirme ve kapanış şeklinde bir sıralama izlendi. Anımsama terapisi uygulama aşamaları içerisinde ilk seansta; kişiler tanıştırıldı, grubun amacı anlatıld, anımsama terapisi uygulaması ve konular hakkında kişiler bilgilendirildi. İkinci seanstan itibaren bir önceki seans konusu genel bir hatırlama yapılarak haftanın seans konusu ile ilgili paylaşımlarda bulunuldu. Seans konusunda terapistin ve katılımcıların getirdiği materyaller üzerine odaklanılarak, anımsanan olumlu anılar, olaylar ve öykü paylaşmaları yapıldı. Her seans sonunda konu hakkında genel bir değerlendirme ile kişilerden geri bildirim alındı. 


\section{Istatiksel Analiz}

Verilerin istatiksel analizinde SPSS 22.00 programı kullanılmıştır. Ölçümle belirtilen değişkenler, Ortalama \pm Standart Sapma $(X \pm S S)$ olarak ifade edilmiş, sayımla belirlenen değişkenler için yüzde (\%) değeri hesaplanmıştır. Çalışmaya katılan bireylerin yaşlılığa uyum ve yaşam kalitesi düzeylerinin müdahale öncesi ve sonrası değerleri Wilcoxon İşaretli sıra testi ile incelenmiştir. Kontrol ve müdahale grubunun değişkenleri arasındaki farkın incelenmesi Mann-Whitney $U$ testi ile yapılmıştır.

\section{SONUÇLAR}

Müdahale ve kontrol grubunun sosyo-demografik bilgileri Tablo 1'de verilmiştir. Müdahale grubundaki

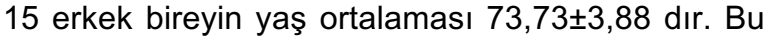
gruptaki bireylerin SMMDT puan ortalaması

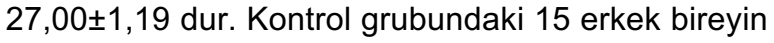
yaş ortalaması 70,86 $\pm 4,15$ dir. Bu gruptaki bireylerin

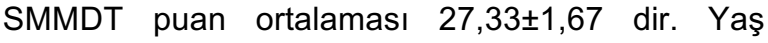
açısından iki bağımsız grup karşılaştırıldığında $(z=1,915 ; p=0,055)$ anlamlı fark yoktur. Olguların büyük bir çoğunluğu evli, eğitim durumları ilk ve orta öğretim düzeyinde ve memur oldukları görülmektedir. Tamamı kendi evinde yaşamaktadır. Büyük bir kısmının düzenliği olarak ilaç kullandığını bazı kardiometabolik hastalıklarının olduğu bildirilmiştir.

Tablo 1. Katılımcıların sosyodemografik bilgileri $(n=30)$

\begin{tabular}{|c|c|c|c|c|}
\hline & \multicolumn{2}{|c|}{$\begin{array}{l}\text { Anımsama terapisi Grubu } \\
\qquad(n=15)\end{array}$} & \multicolumn{2}{|c|}{$\begin{array}{c}\text { Kontrol Grubu } \\
(n=15)\end{array}$} \\
\hline & $\mathbf{n}$ & $(\%)$ & $\mathbf{n}$ & $(\%)$ \\
\hline \multicolumn{5}{|l|}{ Medeni Durum } \\
\hline Bekar & 1 & $(6,7)$ & 2 & $(13,3)$ \\
\hline Evli & 14 & $(93,3)$ & 12 & $(80,0)$ \\
\hline Boşanmış/Ayrı yaşıyor & - & - & 1 & $(6,7)$ \\
\hline \multicolumn{5}{|l|}{ Eğitim Durumu } \\
\hline Okuryazar değil & 1 & $(6,7)$ & - & - \\
\hline İlköğretim & 7 & $(46,7)$ & 5 & $(33,3)$ \\
\hline Lise & 3 & $(20,0)$ & 8 & $(53,3)$ \\
\hline Üniversite & 4 & $(26,7)$ & 2 & $(13,3)$ \\
\hline \multicolumn{5}{|l|}{ Meslek } \\
\hline Çiftçi & 7 & $46,7)$ & - & - \\
\hline Memur & 6 & $(40,0)$ & 9 & $(60,0)$ \\
\hline Esnaf & 2 & $(13,3)$ & 3 & $(20,0)$ \\
\hline İşçi & - & - & 3 & $(20,0)$ \\
\hline \multicolumn{5}{|l|}{ Calışma Durumu } \\
\hline Hiç çalışmamış & 1 & $(6,7)$ & - & - \\
\hline Çalışıyor & 2 & $(13,3)$ & 1 & $(6,7)$ \\
\hline Emekli & 12 & $(80,0)$ & 14 & $(93,3)$ \\
\hline \multicolumn{5}{|l|}{ Çocuk Sayısı } \\
\hline 1 & 1 & $(6,7)$ & 1 & $(6,7)$ \\
\hline 2 & 2 & $(13,3)$ & 4 & $(26,7)$ \\
\hline 3 & 8 & $(53,3)$ & 7 & $(46,7)$ \\
\hline 4 & 2 & $(13,3)$ & 1 & $(6,7)$ \\
\hline 5 & 2 & $(13,3)$ & 2 & $(13,3)$ \\
\hline \multicolumn{5}{|l|}{ İlaç Kullanımı } \\
\hline Düzenli ilaç kullanıyorum & 10 & $(66,7)$ & 14 & $(93,3)$ \\
\hline Hiç ilaç kullanmıyorum & 5 & $(33,3)$ & 1 & $(6,7)$ \\
\hline \multicolumn{5}{|l|}{ Hastalık } \\
\hline Yok & 3 & $(20,0)$ & 2 & $(13,3)$ \\
\hline Hipertansiyon & 5 & $(33,3)$ & 3 & $(20,0)$ \\
\hline Diyabet & - & - & 1 & $(6,7)$ \\
\hline Kardiyovasküler & 2 & $(13,3)$ & 1 & $(6,7)$ \\
\hline Nörolojik & - & - & - & - \\
\hline Ortopedik & 1 & $(6,7)$ & - & - \\
\hline Kanser & - & - & - & - \\
\hline Diğer & 4 & $(26,7)$ & - & - \\
\hline Birden fazla hastalık & - & - & 8 & $(53,3)$ \\
\hline
\end{tabular}


Çalışmamızda anımsama terapisi sonunda müdahale grubunda yer alan bireylerin; Yaşlılığa uyum düzeylerini değerlendiren Yaşlılığa Uyum Güçlüğü Değerlendirme puanında istatistiksel olarak anlamlı bir azalmanın olduğu ( $p=0,001)$ (Tablo 2) dolayısı ile kişilerin yaşlıı̆ga uyum düzeylerinde artış olduğu görülmüştür. Yaşam kalitesini değerlendiren WHOQOL-OLD değerlendirmesinin parametrelerinden özerklik $(p=0,001)$, geçmiş, bugün, gelecek faaliyetleri $(p=0,001)$, sosyal katılım $(p=0,001)$, yakınlık $(p=0,001)$ ve toplam puanda $(p=0,001)$ iyileşme görülmüştür (Tablo 2).

Tablo 2. Grupların uyum ve yaşam kalitesi başlangıç ve sonuç değerlerinin karşılaştırılması

\begin{tabular}{|c|c|c|c|c|c|c|c|c|}
\hline \multicolumn{5}{|c|}{ Anımsama terapisi Grubu } & \multicolumn{4}{|c|}{ Kontrol Grubu } \\
\hline & $\begin{array}{l}\text { Müdahale } \\
\text { Öncesi } \\
\text { X士SS }\end{array}$ & $\begin{array}{l}\text { Müdahale } \\
\text { Sonrası } \\
\text { X士SS }\end{array}$ & $\mathbf{z}$ & $\mathbf{p}$ & $\begin{array}{l}\text { Müdahale } \\
\text { Öncesi } \\
\text { X士SS }\end{array}$ & $\begin{array}{l}\text { Müdahale } \\
\text { Sonrası } \\
\text { X士SS }\end{array}$ & $\mathbf{z}$ & $\mathbf{p}$ \\
\hline YUGDÖ & $8,53 \pm 3,39$ & $4,73 \pm 2,40$ & $-3,423$ & $0,01^{*}$ & $8,86 \pm 3,35$ & $8,60 \pm 3,49$ & $-0,707$ & 0,480 \\
\hline \multicolumn{9}{|l|}{ WHOQOL-OLD } \\
\hline Duyusal işlevler & $8,13 \pm 1,45$ & $8,20 \pm 1,37$ & $-1,000$ & 0,317 & $7,93 \pm 1,27$ & $7,93 \pm 1,09$ & 0,000 & 1,000 \\
\hline Özerklik & $15,33, \pm 1,58$ & $17,53 \pm 1,12$ & $-3,349$ & $0,001^{*}$ & $15,53 \pm 1,59$ & $15,53 \pm 1,59$ & 0,000 & 1,000 \\
\hline $\begin{array}{l}\text { Geçmiş, Bugün, } \\
\text { Gelecek Faaliyetleri }\end{array}$ & $15,53 \pm 1,64$ & $17,26 \pm 1,16$ & $-3,475$ & $0,001^{*}$ & $15,53 \pm 2,47$ & $15,66 \pm 2,58$ & $-1,000$ & 0,317 \\
\hline Sosyal Katılım & $16,00 \pm 1,64$ & $18,00 \pm 0,92$ & $-3,329$ & $0,001^{*}$ & $15,53 \pm 2,19$ & $14,86 \pm 3,41$ & $-0,378$ & 0,705 \\
\hline Ölüm ve ÖImek & $8,60 \pm 1,12$ & $8,60 \pm 1,12$ & 0,000 & 1,000 & $9,00 \pm 1,73$ & $9,00 \pm 1,64$ & 0,000 & 1,000 \\
\hline Yakınlık & $14,46 \pm 2,09$ & $16,40 \pm 1,91$ & $-3,220$ & $0,001^{*}$ & $14,46 \pm 2,32$ & $14,46 \pm 2,16$ & 0,000 & 1,000 \\
\hline Toplam & $78,06 \pm 5,75$ & $86,00 \pm 3,79$ & $-3,413$ & $0,001^{*}$ & $78,00 \pm 5,79$ & $77,46 \pm 5,50$ & $-0,172$ & 0,863 \\
\hline
\end{tabular}

${ }^{*} p<0,05$

Kontrol grubunda yer alan bireylerde anımsama terapisi öncesi ve sonunda aldıkları YUDGÖ ve WHOQOL-OLD puan ortalamaları arasında istatistiksel olarak anlamlı bir değişim saptanmamıştır. Müdahale öncesi anımsama terapisi ve kontrol grubu karşılaştırıldığında ilk değerlendirme sonuçlarına göre YUDGÖ ve WHOQOL-OLD değerlerinde anlamlı bir fark bulunmamıştır (Tablo 3). Grupların homojen olduğu görülmüştür.

Tablo 3. Grupların uyum düzeyi ve yaşam kalitesi başlangıç değerleri karşılaştırılması

\begin{tabular}{|c|c|c|c|c|}
\hline \multicolumn{5}{|c|}{ Müdahale Öncesi } \\
\hline & $\begin{array}{l}\text { Anımsama } \\
\text { Terapisi Grubu }\end{array}$ & Kontrol Grubu & & \\
\hline & XISS & $X \pm S S$ & $\mathbf{z}$ & $\mathbf{p}$ \\
\hline YUGDÖ & $8,53 \pm 3,39$ & $8,86 \pm 3,35$ & $-0,146$ & 0,902 \\
\hline \multicolumn{5}{|l|}{ WHOQOL-OLD } \\
\hline Duyusal işlevler & $8,13 \pm 1,45$ & $7,93 \pm 1,27$ & $-0,319$ & 0,775 \\
\hline Özerklik & $15,33, \pm 1,58$ & $15,53 \pm 1,59$ & $-0,275$ & 0,806 \\
\hline Geçmiş, Bugün, Gelecek Faaliyetleri & $15,53 \pm 1,64$ & $15,53 \pm 2,47$ & $-0,315$ & 0,775 \\
\hline Sosyal Katılım & $16,00 \pm 1,64$ & $15,53 \pm 2,19$ & $-0,064$ & 0,967 \\
\hline Ölüm ve Ölmek & $8,60 \pm 1,12$ & $9,00 \pm 1,73$ & $-0,393$ & 0,713 \\
\hline Yakınlık & $14,46 \pm 2,09$ & $14,46 \pm 2,32$ & $-0,188$ & 0,870 \\
\hline Toplam & $78,06 \pm 5,75$ & $78,00 \pm 5,79$ & $-0,312$ & 0,775 \\
\hline
\end{tabular}


Müdahale sonrası anımsama terapisi ve kontrol grubu karşılaştırıldığında son değerlendirme sonuçlarına göre YUDGÖ ve WHOQOL-OLD bazı parametrelerde anlamlı bir değişim saptanmıştır
(Tablo 4). Anımsama terapisi'nin yaşlılığa uyum ve yaşam kalitesi üzerine iyileştirici etkisi olduğu görülmüştür.

Tablo 4. Grupların uyum düzeyi ve yaşam kalitesi sonuç değerleri karşılaştırılması

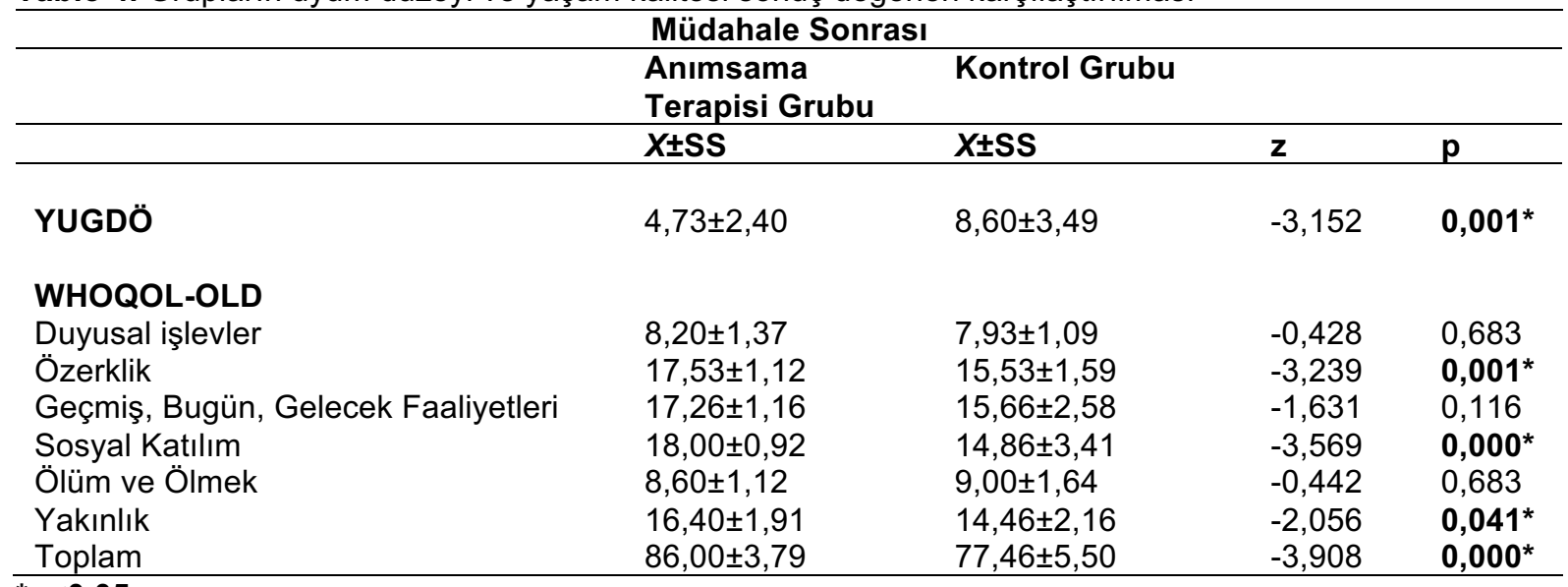

${ }^{*} \mathrm{p}<0,05$

\section{TARTIŞMA}

Geriatrik erkek bireylerde anımsama terapisi'nin yaşlılığa uyum ve yaşam kalitesi üzerine etkisini incelemek amacıyla yapılan çalışmada, müdahale grubunda bulunan bireylerin yaşlılığa uyum güçlüğü düzeylerinde azalma, yaşam kalitesi; özerklik, geçmiş, bugün, gelecek faaliyetleri, sosyal katılım, yakınlık parametrelerinde puansal artış görüldü.

Anımsama terapisi, uygulamadaki kolaylığı, grup halinde uygulanabilmesi, ileri yaştaki bireyler tarafından rahatıkla kabul görmesi gibi nedenlerle yurtdışında yaygın biçimde kullanılmaktadır. Yapılan çeşitli araştırmalarda anımsama terapisi'nin depresyon (Ashida, 2000; Watt ve Cappeliez, 2000; Jones ve Beck-Little, 2002; Hsieh, Chang, Su ve ark, 2010; Bohlmeijer, Smit ve Cuijpers, 2003); ileri yaşlara uyum (Harper, 1993); yas ve kayıplarla aş etme (Rosenblatt ve Elde, 1990); duygusal durum (Trevitt ve MacKinlay, 2006); özyetkinlik duygusu (Rybarczyk ve Auerbach, 1990) ve kuşaklararası iletişim (Larson, 2001) gibi değişkenler üzerinde olumlu etkilerine rastlanmıştır. Ayrıca, anımsama gruplarının kişilerarası etkileşim ve paylaşıma imkân verdikleri, arkadaşlık ve yardımlaşma duygularını pekiştirdikleri, özgüven duygusunu artırdıkları ve rahatlama, iyi hissetme duygularını uyandırdıkları da belirlenmiştir (O'Leary ve Nieuwstraten, 2001).

Moore, Metcalf ve Schow (2006)'un yaptığı çalışmada, arkadaş ve aile ilişkilerinin, sosyal ortamlara katılmanın yaşlılarda yaşamı anlamlandırmada ve yaşamdan zevk almada önemli olduğu saptanmıştır.

Aşiret ve ark. (2018)'ın yaptıkları çalışmada 27 birey müdahale grubunda, 23'ü kontrol grubunda olmak üzere yaşlı kadınların yaşlılığa uyum düzeyindeki bireysel anımsama terapisi'nin etkisini değerlendirilmişler ve müdahale grubundaki katılımcıların uyum düzeylerinde istatistiksel olarak anlamlı bir artış olduğunu bulmuşlardır. Çalışmamızda da anımsama terapisi sonrası bireylerin uyum düzeylerinde anlamlı bir artış olduğu gözlemlenmiştir.

Siviş ve Demir (2007)'in kurumda kalan 70 yaşlı birey ile yaptıkları bir çalışmada anımsama terapisi'nin yaşam doyumu üzerine etkisinin olmadığı fakat bireylerin sosyalleşmesi ve duygusal iyilik hali üzerine olumlu etkisinin olduğunu belirtmişlerdir. Çalışmamızda da bu sonuçlara paralel olarak, grup içerisinde uygulanan anımsama terapisi'nin kişilerin sosyalleşmesine olanak sağladığı gözlemlenmiştir.

Çalışmamızda, anımsama terapisi öncesinde seanslar 'olumlu anıların' paylaşılması yönünde yapılandırılarak seans sırasında oluşabilecek travmalara karşı önlem alınması gerekli görülmüştür. Seans süreci içerisinde odağın yalnızca geçmiş olmamasına dikkat edilmiş ve paylaşımlardan yola çıkarak geçmiş ve bugün arasında bağlantı kurulmasına yardımcı olunmuştur.

Geriatrik bireyler, ortak özellikleri ve yaşam 
tarzları göz önünde bulundurularak gruplara ayrılmıştır. Grup içerisinde yeni arkadaşlık ilişkilerinin oluşması ve ortak konular hakkında fikir alış verişinde bulunulması sosyal katııı ve yakınlık parametrelerinde iyileşme görülmesinde rol oynamıştır. Anısı olan seyahatler konusunun uygulandığı seansa getirilen fotoğraf ve seyahat defterlerinin kişilerde sosyal katılımı olumlu yönde tekrar sorgulattığı gözlemlenmiştir.

Okul dönemine ait mutlu anılar, arkadaşlar ve öğretmenler, gençlik dönemine ait mutlu anılar, iş hayatı ve evililik konularından bahsetmek kişilerin geçmişte elde ettikleri başarıları ve gelecek ile ilgili düşüncelerini sorgulamalarına yardımcı olduğu gözlemlenmiştir. Bu durumun geçmiş, bugün, geleceğe ait aktiviteler parametresinde anlamlı bir iyileşme gözlemlenmesi üzerinde etkili olduğunu düşünmekteyiz.

Ölüm ve ölmek parametresindeki anlamlı bir değişimin gözlemlenmeme sebebinin, geriatrik bireylerin ölüm ile ilgili konuşmaktan kaçınmaları ve hassas davranış sergilemelerinden kaynaklandığını düşünmekteyiz.

Çalışmamızda kişilere uygun seçtiğimiz konuların, bireylerde güçlü yönlerin ve geçmişteki başarıların hatırlanmasına sebep olduğunu böylece, bugün ile geçmiş arasında bağlantı kurarak bugünkü baş etme becerilerinin artmasına olanak sağladığını düşünüyoruz.

Bu çalışma bazı limitasyonlara sahiptir. Birincil olarak, grupların bir araya geleceği erişilebilirliği kolay, uygun ortam bulunması ve hazırlanması limitasyon olarak görülmüştür. Konuya uygun materyal getirilmesinin bazı katılımcılar tarafından unutulması çalışmamızın bir diğer limitasyonu olduğu söylenebilir. Bu kapsamda seans öncelerinde kişilere materyal hatırlatması ve uygun ortamın çalışmadan belli bir süre önce belirlenip hazırlanması gelecekteki çalışmaların sonuçlarını olumlu yönde etkileyeceği düşünüyoruz.

Anımsama terapisi'ne daha geniş örneklem gruplarının dahil edildiği kontrollü ve uzun dönem takipli ergoterapi çalışmalarına intiyaç duyulmaktadır.

\section{Kaynaklar}

Ashida, S. (2000). The effect of reminiscence music therapy sessions on changes in depressive symptoms in elderly persons with dementia. J Music Ther, 37(3), 170-182. https://doi.org/10.1093/jmt/37.3.170

Aşiret, G. D., \& Dutkun, M. (2018). The effect of reminiscence therapy on the adaptation of elderly women to old age: A randomized clinical trial. Complement Ther Med, 41, 124129. https://doi.org/10.1016/j.ctim.2018.09.018

Avaş, S., \& Akçiçek, F. (2010). Kapsamlı geriatrik değerlendirme. Ege Tıp Dergisi, 49(3), 19-30. http://egetipdergisi.com.tr/download/article-file/350444

Bohlmeijer, E., Smit, F., \& Cuijpers, P. (2003). Effects of reminiscence and life review on late-life depression: Int $\mathrm{J}$ Geriatr Psychiatry, 18(12), 1088-1094. https://doi.org/10.1002/gps.1018

Bowling, A. (2007). Quality of life in older age: What older people say. In Mollenkopf, H., Walker, A. (Eds.), Quality of life in old age. Dordrecht, the Netherlands: Springer Publication (pp. 15-30).

Bulduk, S., Dinçer, Y., Usta, E., \& Bayram, S. (2017). Demanslı yaşılıara uygulanan sanat terapi yönteminin bilişsel durum üzerine etkisinin incelenmesi. J Altern Complement Med, 7(1), 36-41. https://doi.org/10.16899/gopctd.95724

Cangöz, B. (2009). Hafif bilişsel bozuklukta nöropsikolojik değerlendirme. nörolojide yeni ufuklar: Alzheimer hastalığı ve diğer demanslar. Ankara: Güneş Tıp Kitabevi (s. 97-108.).

Coleman, P. G. (2005). Uses of reminiscence: Functions and benefits. Aging Ment Health, 9(4), 291-294. https://doi.org/10.1080/13607860500169641

Çelebi, Ç. D., \& Yüksel, M. Y. (2014). Yaşlılık ve yaşılıara sunulan psikolojik danışma ve rehberlik uygulamalarına bir bakış. Kalem Eğitim ve İnsan Bilimleri Dergisi, 4(2), 175-202.

Eser, S., Saatli, G., Eser, E., Baydur, H., \& Fıdaner, C. (2010). Yaşlılar için dünya sağlık örgütü yaşam kalitesi modülü WHOQOL-OLD: Türkiye alan çalışması Türkçe sürüm geçerlilik ve güvenilirlik sonuçları. Turk Psikiyatri Derg, 21(1), 37-48.

Gignac, M. A., Cott, C., \& Badley, E. M. (2002). Adaptation to disability: Applying selective optimization with compensation to the behaviors of older adults with osteoarthritis. Psychol Aging, 17(3), 520-524. https://doi.org/10.1037/0882-7974.17.3.520

Görgünbaran, A. (2008). Yaşlılıkta sosyalizasyon ve yaşam kalitesi. Yaşlı Sorunları Araştırma Dergisi, 1(2), 86-97. http://dergipark.org.tr/download/article-file/203230

Güngen, C., Ertan, T., Eker, E., Yaşar, R., \& Engin, F. (2002). Standardize Mini Mental Test'in Türk toplumunda hafif demans tanısında geçerlik ve güvenilirliği. Turk Psikiyatri Derg, 13(4), 273-281.

Güven, S., Şener, A., \& Gürsoy, N. (2012). Women's Views on Old Age. The International Journal of the Humanities, 9(5), 88-92.

Harper, D. J. (1993). Remembered work importance, satisfaction, reminiscence and adjustment in retirement: $A$ case study. Couns Psychol Q, 6 (2), 155-164. https://doi.org/10.1080/09515079308254503

Haight, B., \& Gibson, F. (2005). Working with older adults: Group process and technique. Mississauga: Jones \& Bartlett Publishers.

Hoffmann, A. A., \& Parsons, P. A. (1988). The analysis of quantitative variation in natural populations with isofemale strains. Genet Sel Evol, 20(1), 87-98. https://doi.org /10.1186/1297-9686-20-1-87

Hsieh, C. J., Chang, C., Su, S. F., Hsiao, Y. L., Shih, Y. W., Han, W. H., \& et al. (2010). Reminiscence group therapy on depression and apathy in nursing home residents with mild-to-moderate dementia. J Exp Clin Med, 2(2), 72-78. 
https://doi.org/10.1016/S1878-3317(10)60012-5

Jones, E. D., \& Beck-Little, R. (2002). The use of reminiscence therapy for the treatment of depression in rural-dwelling older adults. Issues Ment Health Nurs, 23(3), 279-290. https://doi.org/10.1080/016128402753543018

Jonsdottir, H., Jonsdottir, G., Steingrimsdottir, E. \& Tryggvadottir, B. (2001). Group reminiscence among people with end-stage chronic lung diseases. J Adv Nurs, 35 (1), 79-87. https://doi.org/10.1046/j.13652648.2001.01824.x

Karimi, H., Dolatshahee, B., Momeni, K., Khodabakhshi, A., Rezaei, M., \& Kamrani, A. A. (2010). Effectiveness of integrative and instrumental reminiscence therapies on depression symptoms reduction in institutionalized older adults: An empirical study. Aging Ment Health, 14(7), 881887. https://doi.org/10.1080/13607861003801037

Kurt, G., Yücel Beyaztaş, F., \& Erkol, Z. (2010). Yaşlıların sorunları ve yaşam memnuniyeti. Adli Tıp Dergisi, 24(2), 32-39.

https://www.journalagent.com/adlitip/pdfs/ADLITIP_24_2 _32_39.pdf

Kutsal, G. Y. (2003). Yaşlanan insan ve yaşlanan toplum. Hacettepe Toplum Hekimliği Bülteni, 22(3-4). http://www.thb.hacettepe.edu.tr/arsiv/2003/sayi_34/baslik1.pdf

Larson, R. H. (2001). Memories groups. Clergy Journal, 77 (3), 34-36.

http://web.a.ebscohost.com/ehost/pdfviewer/pdfviewer?vid=0 $\&$ sid=d359143c-9dcb-4120-862189fb84511a1d\%40sessionmgr4008

Lin, Y. C., Dai, Y. T., \& Hwang, S. L. (2003). The effect of reminiscence on the elderly population: A systematic review. Public Health Nurs, 20(4), 297-306. https://doi.org/10.1046/j.1525-1446.2003.20407.x

Liu, S. J., Lin, C. J., Chen, Y. M., \& Huang, X. Y. (2007). The effects of reminiscence therapy on self-esteem, depression, loneliness and life satisfaction of elderly people living alone. Mi- Taiwan J of Med, 12(3), 133-142. https://doi.org/10.6558/MTJM.2007.12(3).2

Moore, S. L., Metcalf, B., \& Schow, E. (2006). The Quest for Meaning in Aging. Geriatr Nurs, 27(5), 293-299. https://doi.org/10.1016/j.gerinurse.2006.08.012

O'Leary, E., \& Nieuwstraten, I. M. (2001). The exploration of memories in Gestalt reminiscence therapy. Couns Psychol Q, 14(2), 165-180. https://doi.org/10.1080/09515070110057522

Ouwehand, C., de Ridder, D. T., \& Bensing, J. M. (2007). A review of successful aging models: Proposing proactive coping as an important additional strategy. Clin Psychol Rev, 27(8), 873-884. https://doi.org/10.1016/j.cpr.2006.11.003

Proietti, M. G., Compagnone, T., \& Liotta, G. (2014) Addressing healthcare needs in older people after discharge. Adv Aging Res, 3(03), 257-264. http://dx.doi.org/10.4236/aar.2014.33035

Rybarczyk, B. D. \& Auerbach, S. M. (1990). Reminiscence interviews as stress management interventions for older patients undergoing surgery. Gerontologist, 30 (4), 522528. https://doi.org/10.1093/geront/30.4.522

Rosenblatt, P., \& Elde, C. (1990). Shared reminiscence about a deceased parent: Implications for grief education and grief counseling. Fam Relat, 39 (2), 206-210. http://dx.doi.org/10.2307/585725
Siviş, R., \& Demir, A. (2007). The efficacy of reminiscence therapy on the life satisfaction of Turkish older adults: A preliminary study. Turk J Gerıatr, 10(3), 131-137. http://www.geriatri.dergisi.org/uploads/pdf/pdf_TJG_363. pdf

Şişman, F. N., \& Kutlu, Y. (2016). Yaşlılarda Uyum Güçlüğünü Değerlendirme Ölçeği'nin (YUGDÖ) geliştirilmesi ve psikometrik özellikleri. Int J Psychiatr Nurs Res, 7(1), 2533. https://doi.org/10.5505/phd.2016.82905

Trevitt, C., \& MacKinlay, E. (2006). "I Am Just an Ordinary Person..." Spiritual Reminiscence in Older People with Memory Loss. J Relig Spiritual Aging, 18(2/3), 79-91. https://doi.org/10.1300/J496v18n02_07.

Watt, L. M., \& Cappeliez, P. (2000). Integrative and instrumental reminiscence therapies for depression in older adults: Intervention strategies and treatment effectiveness. Aging Ment Health, 4(2),166-177. https://doi.org/10.1080/13607860050008691 